Fetal Diagnosis and Therapy
Fetal Diagn Ther 2019;45:365-372

DOI: $10.1159 / 000497472$
Received: September 10, 2018

Accepted after revision: January 31, 2019

Published online: March 21, 2019

\title{
Amnioinfusions to Treat Early Onset Anhydramnios Caused by Renal Anomalies: Background and Rationale for the Renal Anhydramnios Fetal Therapy Trial
}

\author{
Elizabeth M. O'Hare ${ }^{\mathrm{a}}$ Angie C. Jelin ${ }^{\mathrm{b}}$ Jena L. Miller ${ }^{\mathrm{b}}$ Rodrigo Ruano $^{\mathrm{e}}$ \\ Meredith A. Atkinson ${ }^{c}$ Ahmet A. Baschat ${ }^{b}$ Eric B. Jelin ${ }^{d, b}$ \\ a Johns Hopkins University, Baltimore, MD, USA; ${ }^{b}$ Gynecology and Obstetrics, Johns Hopkins University, Baltimore,

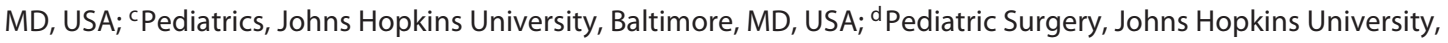 \\ Baltimore, MD, USA; ${ }^{e}$ Obstetrics and Gynecology, Mayo Clinic, Rochester, MN, USA
}

\section{Keywords}

Anhydramnios - Amnioinfusions - Bilateral renal agenesis .

Pulmonary hypoplasia $\cdot$ Renal replacement therapy

\section{Abstract}

Anhydramnios caused by early anuria is thought to be universally fatal due to pulmonary hypoplasia. Bilateral renal agenesis and early fetal renal failure leading to anhydramnios constitute early pregnancy renal anhydramnios (EPRA). There have been successful reports of amnioinfusions to promote lung growth in the setting of EPRA. Some of these successfully treated EPRA fetuses have survived the neonatal period, undergone successful dialysis, and subsequently received a kidney transplant. Conversely, there are no reports of untreated EPRA survivors. This early success of amnioinfusions to treat EPRA justifies a rigorous prospective trial. The objective of this study is to provide a review of what is known about fetal therapy for EPRA and describe the Renal Anhydramnios Fetal Therapy trial. We review the epidemiology, pathophysiology, and genetics of EPRA. Furthermore, we have performed systematic review of case reports of treated EPRA. We

\section{KARGER}

(c) 2019 S. Karger AG, Basel

E-Mail karger@karger.com

www.karger.com/fdt describe the ethical framework, logistical challenges, and rationale for the current single center (NCT03101891) and planned multicenter trial.

(c) 2019 S. Karger AG, Basel

\section{Introduction}

Anhydramnios secondary to anuria before 22 weeks gestational age (GA) is thought to be universally fatal [1$4]$. Mortality results because amniotic fluid plays an essential role in lung development and its prolonged absence before viability leads to severely hypoplastic lungs. Urine first contributes to amniotic fluid by 10 weeks GA and constitutes over $90 \%$ of fluid volume by week 16 , so sufficient renal function by 16 weeks GA is necessary to avoid anhydramnios (although oligohydramnios may be

Presented as oral presentation at the 37th Annual Meeting of the International Fetal Medicine and Surgery Society, August 7-12, 2018, Bali, Indonesia. 
present by week 10) [5]. Congenital bilateral renal agenesis (CoBRA) and early gestation fetal renal failure (FRF) before 22 weeks GA result in anuria and anhydramnios. Together these entities constitute early pregnancy renal anhydramnios (EPRA).

\section{Epidemiology of EPRA}

CoBRA is one of the most common malformations of the urinary tract, affecting 1-2 of every 3,000 fetuses [6]. It is characterized by the complete lack of renal tissue with ensuing anhydramnios and secondary pulmonary hypoplasia $[7,8]$. Potter's syndrome, a historical term used to describe the typical appearance of a neonate exposed to anhydramnios, is additionally characterized by flattened facial features and limb deformities, due to intrauterine compression and insufficient nutrients, along with pulmonary hypoplasia caused by anhydramnios. CoBRA can be diagnosed when no renal tissue is identified by sonography at 12-14 weeks GA [6] and anhydramnios with no bladder filling at 16 weeks GA [5].

FRF is typically a result of bilateral multicystic dysplastic kidney (MCDK) disease but can also result from autosomal recessive polycystic kidney disease (ARPKD) and early-onset severe lower urinary tract obstruction (LUTO) with complete bladder outlet obstruction. Ruano et al. [2] found increased risk of FRF when bladder refilling is less than $27 \%$ within 2 days after vesicocentesis in LUTO. MCDK is characterized by non-communicating abnormal cysts that replace renal parenchyma. It can be diagnosed between 15 and 20 weeks GA when cysts are evident [1]. The incidence of MCDK is 1 in 1,000-4,300, but in a study of 73 patients, all fetuses with bilateral MCDK $(n=3)$ or unilateral MCDK and contralateral renal agenesis $(n=1)$ along with anhydramnios died within the first $24 \mathrm{~h}$ of life [1]. Only one of the 4 newborns with bilateral MCDK survived past this period to 9 days of life, since the fetus had oligohydramnios rather than anhydramnios in utero. LUTO is characterized by urethral obstruction with bilateral hydroureteronephrosis and a dilated bladder. Its incidence is reported between 1 in 2,000 to 1 in 25,000 births [9]. It is usually diagnosed between late second and early third trimester [2]. In severe cases, the kidneys cease to produce urine (anuria) and anhydramnios develops. In a retrospective study, Ruano et al. [2] found that severe LUTO leading to FRF and anhydramnios early in pregnancy led to severe pulmonary hypoplasia and fetal or neonatal demise in all cases. ARPKD is a congen- ital hepatorenal cystic disorder [10]. Its incidence is about 1 in 40,000 [11] and about one-third to one-half of newborns with ARPKD die shortly after birth due to pulmonary insufficiency [10]. It is typically diagnosed during the second trimester, although it can be detected during the late first trimester.

Since there is no bladder filling in the setting of CoBRA and FRF, vesicoamniotic shunting is not an option. Therefore, CoBRA and FRF leading to EPRA were previously thought to be universally fatal secondary to severe pulmonary hypoplasia or umbilical cord compression [12], but an experiment of nature suggests that replacement of the amniotic fluid can prevent respiratory failure [13]. This experiment involved monoamniotic twins discordant for CoBRA. The CoBRA twin who shared amniotic fluid with the normal co-twin did not demonstrate respiratory failure at birth. This case justified a later intervention by Bienstock et al. [14] to promote lung growth in CoBRA with amnioinfusions. This and 8 other case reports have documented adequate neonatal lung function when amnioinfusions were given prenatally in the setting of EPRA [12, 14-16]. These outcomes raise the possibility of pulmonary survival for infants with a disease previously thought to be fatal.

\section{Genetic Causes of CoBRA and FRF}

The genetic cause of ARPKD is a mutation in the PKHD1 gene [10]. However, the pathologies of CoBRA and FRF (specifically MCKD and LUTO) are largely unknown, since many genetic and epigenetic factors contribute, but some genes have been identified. Multiple gene-knockouts in murine models have resulted in CoBRA, including the homozygous recessive mutation of FGF20 [17] and the integrin $\alpha 8$-encoding gene (ITGA8) [18]. The ITGA8 gene is expressed in the metanephric mesenchyme and plays a crucial role in renal development. When mutated, ITGA 8 causes abnormal interaction of the uretic bud with the metanephric mesenchyme. Other genes such as Hs2st $[19,20]$ and GDNF [21], which play a role in mesenchyme-to-epithelial conversion and branching of the uretic bud may also lead to CoBRA. Inheritance patterns have implicated an autosomal dominant gene that causes renal agenesis, with the presence of incomplete penetrance or non-penetrance and variable expressivity [22]. Partial duplication of the short arm of chromosome 11 has been identified in cases of posterior urethral valves, the most common presentation of LUTO [23]. Moreover, in 
unilateral MCDK, HNF1B mutation has been identified, although the genetics of bilateral MCDK vary greatly [24]. Although some possible genetic contributors are reported, the specific genetic causes of these diseases remain largely elusive.

\section{Effects of EPRA on Fetal Lung Development}

EPRA affects lung distention and growth by compressing the thoracic cavity and allowing fetal lung fluid to escape from the lungs. Lung fluid volume increases with lung weight and by the third trimester, epithelial secretions in the fetal lungs produce about $25 \mathrm{~mL} / \mathrm{kg}$ of lung fluid, which composes about $90 \%$ of the lung weight [25]. During fetal breathing movements, fluid passes through the trachea and is swallowed or it mixes with the amniotic fluid. During non-breathing periods, the positive pressure of amniotic fluid in the upper respiratory tract inhibits egress of lung fluid, keeping it retained within the trachea by the glottis. This creates a transpulmonary pressure gradient that is necessary for maintaining alveolar distension above newborn functional residual capacity and promoting lung growth [26-28]. The correlation between lung fluid and lung growth was first explained by Alcorn et al. [29] using a fetal lamb model. They found that chronic tracheal drainage to decrease lung fluid volume led to lung hypoplasia, whereas tracheal ligation caused lung distension and hyperplasia. Similarly, amniotic fluid is necessary for keeping lung fluid within the lungs to promote alveolar distension and growth and for maintaining this transpulmonary gradient [25, 30-32]. Low amniotic fluid volume allows lung fluid to drain from the trachea and leads to alveolar compression.

Prior to fetal micturition in the first trimester, placental, dermal, and membrane secretions are responsible for producing amniotic fluid [5]. Between 8 and 10 weeks GA, a normal fetus begins to produce urine, which makes up most ( $>90 \%$ ) of the amniotic fluid by 16 weeks GA. Urine is not only important for maintaining lung distension but also contains proline that is necessary for lung maturation because of its vital role in collagen and mesenchyme formation and development [33-35]. In the setting of EPRA, the kidneys are absent or non-functional and therefore do not produce urine to contribute to amniotic fluid. This affects lung distension and maturation without proline and leads to pulmonary hypoplasia, which prevents neonatal survival as the severely hypoplastic lungs cannot conduct sufficient gas exchange postnatally.

Amnioinfusions for Renal Anhydramnios: Rationale for the RAFT Trial

\section{Rationale for Fetal Therapy to Promote Lung Development}

Expertise in the provision of neonatal renal replacement therapy (RRT) has increased in the past 20 years, and chronic dialysis is offered to nearly all infants with isolated end-stage renal disease (ESRD) who survive the neonatal period [36-37]. The 5-year survival rate for neonates who initiatechronic dialysis in the first month of life is $90 \%$, and among these patients $80 \%$ transition to renal transplantation by 5 years of age [37-38]. However, chronic RRT is not indicated in neonates with other, lifelimiting comorbidities and poor prognoses. The ethical issues around initiating chronic dialysis in neonates with other organ system diseases likely limit viability are complex and have been discussed by Lantos et al. [39] and Wightman et al. [40]. Many factors affect decision making and should be discussed thoroughly with the parents and the fetal/pediatric/nephrology care team before proceeding with treatment [40]. Renal transplantation is the preferred mode of chronic RRT for all children with ESRD to reduce long-term morbidity and mortality and to optimize growth and development $[38,41,42]$. A large study by the United States Renal Data System found that hospitalization and infection rates were significantly lower in pediatric patients who received a transplant compared to those on long-term dialysis [43]. This same study found that transplant patients had lower cardiovascular mortality rates, decreased mortality from infection, and improved 5-year survival compared to patients on chronic dialysis. Although the specific underlying causes of ESRD in neonates with a history of EPRA will vary, outcomes for infants on chronic RRT without other significant comorbidities is generally favorable, and renal transplantation is a feasible option once adequate growth has occurred [37].

The expanded accessibility and success of neonatal RRT have helped to rationalize amnioinfusions in the setting of EPRA. Severe pulmonary hypoplasia secondary to EPRA results in the death of the neonate soon after birth due to pulmonary insufficiency. However, if lung development can be promoted in-utero, affected neonates may have increased likelihood of lung function and thus survival and can then be treated for the ESRD associated with CoBRA or FRF with chronic RRT. Serial saline amnioinfusions restore the natural uterine environment and reestablish transpulmonary pressure and alveolar distension. Supplementing proline by amnioinfusions may also be beneficial because of its essential role in collagen formation and pulmonary maturation, although its prophylac- 
tic use in this setting has not been studied. Amnioinfusions are routinely used in ultrasound assessments and diagnoses for fetuses with low fluid volumes [12], but the risk of preterm premature rupture of membranes (PPROM) is still at least $1 / 300$ per infusion. However, the safety of repeated amnioinfusions as a preventative method has been illustrated in multiple studies [2, 4, 8, 14], including a retrospective study of 61 patients presenting with severe oligo-anhydramnios from PPROM who received amnioinfusions with no fatalities recorded as a direct result of treatment. Mothers receiving amnioinfusions for pregnancies complicated by oligohydramnios resulting from early PPROM (16-26 weeks GA) had similar fetal survival as pregnancies complicated by PPROM without oligohydramnios [44].

Although there have been no adequately powered large-scale studies investigating the efficacy of amnioinfusions to treat EPRA, there have been multiple case reports of pulmonary survival in neonates treated with prenatal amnioinfusions for palliation of EPRA and we hypothesize that about $25 \%$ of fetuses receiving amnioinfusions will develop functioning lungs [12]. In 1994, a neonate with CoBRA survived early neonatal life after amnioinfusions were administered from 17 to 33 weeks GA, but ultimately succumbed to dialysis complications after 23 days of life [15]. In 2014, Bienstock et al. [14] reported the case of CoBRA in a 34-year-old woman treated with weekly serial amnioinfusions beginning at 24 weeks GA. The infant was born at 29 weeks GA with age-appropriate lung function and received a kidney transplant from her father after 3 years on chronic peritoneal dialysis [12]. Including the patient in this case report, 2 of 4 CoBRA patients treated with serial amnioinfusions at the authors' institution have survived and successfully undergone renal replacement therapy. At another institution, weekly amnioinfusions were administered for a pregnancy complicated by EPRA beginning at 24 weeks GA. The infant had sufficient pulmonary function at birth but succumbed to dialysis complications and peritonitis after 5 months of life [16].

In a series of 8 pregnancies complicated by fetal LUTO with severe oligo-/anhydramnios in which an amnioport was placed to deliver saline infusions, there were no fetal losses and all 8 subjects had restoration and maintenance of amniotic fluid levels. One subject received only 2 infusions prior to PPROM, and the neonate was noted to have laryngeal web and did not survive. Of the remaining 7 subjects who underwent a mean 14.3 amnioinfusions prior to delivery, 3 did not survive the neonatal period [4]. An additional infant died from complications of dialysisassociated peritonitis at 3 months. The remaining 3 sub- jects who survived the neonatal period were living after successful renal transplantation at the time of publication in 2016 [4]. Haeri et al. [45] additionally reported 2 cases of adequate neonatal lung function after amnioinfusions in the setting of FRF caused by severe LUTO with anuria and anhydramnios before 22 weeks $\mathrm{GA}$, with both infants successfully transitioned to chronic peritoneal dialysis and discharged home. These cases illustrate the potential efficacy of serial amnioinfusions to promote normal lung development and post-natal pulmonary viability in neonates affected by EPRA such that they can progress to RRT for management of their renal failure.

\section{Approach to Fetal and Neonatal Therapy for EPRA}

Treatment for EPRA in the single-center and multicenter Renal Anhydramnios Fetal Therapy (RAFT) trial begins with diagnostic and then serial amnioinfusions before 26 weeks GA in appropriately counseled eligible patients. If patients have adequate respiratory function after birth, the next step is neonatal dialysis (peritoneal dialysis or hemodialysis) and subsequent early childhood kidney transplant. Serial amnioinfusions involve the infusion of normal saline into the amniotic cavity to restore the aqueous environment of the fetus (normal volumes: $25 \mathrm{~mL}$ at 10 weeks, $400 \mathrm{~mL}$ at 20 weeks, $800 \mathrm{~mL}$ at 28 weeks GA) [8]. The timing and frequency of amnioinfusions, along with the optimal timing of delivery, remain uncertain [46]. If pulmonary development is sufficient after birth, neonates will require RRT, including chronic dialysis and kidney transplant. Although hemodialysis is possible in infants ( $<1$ year old), PD is the preferred dialysis modality given the limitations of vascular access infants and the potential for daily dialysis performed at home in infants [36, 47-50].

Renal transplantation is the treatment of choice for children with ESRD and should be performed as soon as is technically possible. Early transplant is recommended to avoid cardiovascular morbidity and infection risk associated with long-term dialysis [51-53]. Size at the time of transplant varies with some centers transplanting infants as small as $5 \mathrm{~kg}$, but most providers aim for transplant once the child is $>10 \mathrm{~kg}$. Living donor transplants demonstrate improved graft survival in infants than those from deceased donors, especially if the donor is a parent [50]. Complete reconstructive urologic surgery is necessary for CoBRA patients who lack a urinary tract, and a pediatric urologist should be incorporated into the multidisciplinary care team to determine the optimal timing 
of urologic surgery relative to renal transplantation. Infants with FRF are likely to respond better to RRT, since a urinary tract exists and may not require complete reconstructive surgery, unless irreparable damage occurred in utero.

\section{Maternal and Fetal Risks of Amnioinfusions to Treat EPRA}

Although the maternal/fetal risk profile of serial amnioinfusions is generally well known, the risks of serial amnioinfusions in an EPRA pregnancy have never been systematically studied. For the mother these risks include rupture of membranes, preterm labor, bleeding, chorioamnionitis, placental abruption, uterine rupture, amniotic fluid embolism, local discomfort, or abdominal discomfort after infusion. As part of an informed consent process, these potential risks must be thoroughly explained to and understood by a potential RAFT participant. The RAFT trial will permit quantification of maternal risks, which in turn will become a critical component of pre-intervention counseling. Fetal risk must also be considered. Because the intervention entails use of relatively small needles, significant fetal injury is extremely unlikely. More likely, however, is the induction of PPROM, preterm labor and prematurity. This may result is severe morbidity and mortality for the EPRA neonate but must be weighed against the near certain mortality of continuing the pregnancy without therapy.

\section{Ethical Considerations for Amnioinfusions to Treat EPRA}

The primary purpose of amnioinfusions in the setting of EPRA is to permit repressurization of the fetal tracheobronchial tree and promote pulmonary development, thus increasing the fetus's chance of survival outside the womb. Pulmonary hypoplasia cannot currently be addressed by post-uterine treatment so without uterine intervention, the neonate will succumb to pulmonary insufficiency shortly after birth. Therefore, fetal intervention is the only plausible treatment for EPRA-associated pulmonary hypoplasia and is currently the only treatment option for a fetus with an otherwise-lethal condition. Current evidence for the effectiveness of amnioinfusions to prevent pulmonary hypoplasia and induce pulmonary survival is limited to case reports. Any neonate with adequate lung function to enable early neonatal survival will subsequently require life-long RRT. ESRD patients require multiple procedures including placement of dialysis access and often central venous access, likely gastrostomy tube placement with supplemental nutritional support, and urologic reconstruction and transplantation. Renal transplantation requires exposure to a variety of medications including immunosuppressive medications, antibiotics/anti-virals, and other drugs to treat transplant side effects [54]. Decisions about prenatal therapies for EPRA should be made cooperatively between families and members of the medical team, with the life-long effects of neonatal ESRD in mind, including the ethical, financial, and societal implications.

Parents of children with chronic illness experience increased levels of illness-related parenting stress secondary to multiple factors including, but not limited to, demanding treatment regimens, financial burdens, and feelings of loss of control [55]. Parents of children with kidney disease in particular report difficulties balancing responsibilities as caregivers with personal self-care [56]. There is a need for intervention efforts aimed at preventing or reducing parenting stress among caregivers of children with chronic illness, but few specific interventions have been developed to accomplish this. Thus, it is critical that parents who are contemplating raising a child with ESRD receive counseling regarding the potential family impact associated with this disease, and must be referred as soon as possible to appropriate social work and psychological services to help navigate the many demands of caregiving that will not be met by the primary medical team. The RAFT trial will follow survivors until 3-4 years after transplant to assess the short- and long-term quality of life in these patients and their families.

Sugarman et al. [46] have summarized the ethical issues around amnioinfusions to treat pulmonary hypoplasia in CoBRA and are summarized here to encompass all diagnoses resulting in EPRA. This analysis should be a part of the decision-making process before beginning a research trial. First, a confirmed diagnosis of EPRA is necessary to ensure appropriate prenatal counseling and treatment. Once the diagnosis is made, it is critical that the family is counseled properly by the multidisciplinary team and fully understands the risk and uncertainty of treatment, to avoid giving false hope. Patients should be counseled appropriately about the possibility of termination. Language that indicates bias for or against treatment should be avoided to allow the family to make an independent decision [46]. The family should be informed on the likelihood of survival for the neonate and potential complications for the pregnancy. There is no guarantee that the fetus will survive to birth and any decision to initiate RRT will be made by the multidisciplinary team considering prognosis and other organ system viability. Furthermore, families must be informed of the risk of mor- 
tality for infants on dialysis and the conditions under which the infant will be a candidate for renal transplantation. These risks need to be thoroughly explained to the parents and formal consent obtained before administering amnioinfusions as part of a research study to determine the efficacy of this intervention for treating pulmonary hypoplasia. It is also essential that the family understands that although theymaywithdraw their participation from a research protocol at any time, early survival of a neonate with CoBRA or FRF will mean a lifetime of RRT with its attendant risks.

The ethical considerations of beginning chronic dialysis in infants are explained in the Clinical Practice Guideline on Shared Decision-Making in the Appropriate Initiation of and Withdrawal from Dialysis by the Renal Physicians Association and American Society of $\mathrm{Ne}-$ phrology [57]. These are objective recommendations intended to assist providers in guiding families through the process of dialysis decision making and to limit futile or inappropriate administration of dialysis. The consensus is to administer dialysis only when the benefits of treatment outweigh the burdens. Therefore, if severe comorbidities and/or death are inevitable, it may not be in the best interest of the patient for dialysis to be initiated or continued.

The societal and economic implications for survival of infants with EPRA should be considered, since most will require extended medical care, using resources from a strained system. Surviving EPRA patients who do not have a living kidney donor will likely pull from the insufficient deceased kidney donor pool. The financial effects on families and hospitals should also be considered. ESRD care is, by definition, lifelong. Medicare and qualifying Medicaid recipients should be reimbursed for RRT and associated treatments, but there may be uncovered expenses that place a financial burden on the family [58] Fetal therapy candidates should not be refused based on financial circumstances and an effort should be made to assist these families financially [46]. Cost-effectiveness models may also be beneficial in the future when more data is available for these patients to help determine in which cases fetal treatment should be administered [12].

In light of these ethical issues, further discussed elsewhere [46], the multidisciplinary team should take care to counsel interested families before beginning amnioinfusions in the context of a trial. If fetal comorbidities are few or are a direct result of EPRA, serial amnioinfusions may be a beneficial treatment, but success in each step of treatment, from fetal therapy to transplant surgery to long-term adherence to immunosuppressive regimens, is necessary to optimize long-term outcomes. Given that neonatal RRT effectively treats ESRD, the efficacy of amnioinfusions in a larger cohort requires evaluation in a formal prospective trial. This can best be done in a multicenter network study with a centralized IRB. This centralized IRB is currently under review protocol is currently under review at Johns Hopkins and has been approved by the North American Fetal Therapy Network.

\section{Rationale for the RAFT Trial}

If lung maturation can be induced in utero by serial amnioinfusions in the setting of EPRA, affected neonates have the potential for long-term survival beyond the perinatal period. Currently the evidence for the efficacy of amnioinfusion is limited to several case reports. Although these reports have been met with great fanfare and enormous lay interest, they do not provide sufficient evidence to prove generalizability. The reports are numerous enough, however, to elevate this field of study from the innovation to research phase. The next step is to conduct a multicenter study and analyze the short-term risks and long-term outcomes of amnioinfusions for treatment of EPRA-associated pulmonary hypoplasia. In August of 2016, the National Institute of Child Health and Human Development and the National Institute of Diabetes and Digestive Kidney Diseases sponsored a workshop and proposed a research agenda for the study of procedures to treat fetal pulmonary manifestations of anhydramnios, confirming the need for systematic study of this intervention [59]. The current status quo of a single site IRB approved prospective trial with many backdoors for therapy in other centers is suboptimal both for advancing the field and providing generalizable knowledge as well as for patient access to potentially life-saving therapy. A multicenter NAFTNet prospective trial with a central IRB will address these issues and is near initiation.

\section{Conclusion}

Serial amnioinfusions in the setting of EPRA may alleviate fetal pulmonary hypoplasia and improve neonatal survival in a previously fatal disease. A large-scale prospective study with strict inclusion/exclusion criteria is necessary to determine the efficacy and safety of amnioinfusions to promote lung development and assess longterm outcomes of dialysis and kidney transplant. A clinical study evaluating the efficacy of amnioinfusions for fe- 
tuses with CoBRA is currently underway at Johns Hopkins Hospital (NCT03101891) and a larger multicenter North American fetal therapy network-based trial has been formulated and is under evaluation by a central IRB.

\section{Acknowledgment}

Trial innovation Network and North American Fetal Therapy Network for guidance throughout trial formulation period.

\section{Statement of Ethics}

The authors have no ethical conflicts to disclose. The Johns Hopkins Institutional review Board has approved the single site "Renal Agenesis Fetal Therapy" trial and is actively reviewing the multicenter "RAFT" trial.

\section{Disclosure Statement}

The authors declare that they have no conflicts of interest to disclose.

\section{Funding Source}

Johns Hopkins Children's Center Innovation Grant has been received for this study.

\section{Authors Contribution}

E.B.J.: study conception, E.M.O., E.B.J., J.L.M., M.A.A., R.R., A.A.B., and A.C.J.: study design, E.M.O., E.B.J., A.C.J., and M.A.A.: manuscript writing, E.B.J., J.L.M., A.A.B., M.A.A., R.R., A.C.J.: critical review.

\section{References}

1 Balasundaram M, Chock VY, Wu HY, Blumenfeld YJ, Hintz SR. Predictors of poor neonatal outcomes in prenatally diagnosed multicystic dysplastic kidney disease. J Perinatol. 2018 Jun;38(6):658-64.

2 Ruano R, Safdar A, Au J, Koh CJ, Gargollo P, Shamshirsaz AA, et al. Defining and predicting 'intrauterine fetal renal failure' in congenital lower urinary tract obstruction. Pediatr Nephrol. 2016 Apr;31(4):605-12.

3 Kizilcan F, Tanyel FC, Cakar N, Büyükpamukçu N, Hiçsönmez A. The effect of low amniotic pressure without oligohydramnios on fetal lung development in a rabbit model. Am J Obstet Gynecol. 1995 Jul;173(1):36-41.

4 Polzin WJ, Lim FY, Habli M, Van Hook J, Minges M, Jaekle R, et al. Use of an amnioport to maintain amniotic fluid volume in fetuses with oligohydramnios secondary to lower urinary tract obstruction or fetal renal anomalies. Fetal Diagn Ther. 2017;41(1):51-7.

5 Dias T, Sairam S, Kumarasiri S. Ultrasound diagnosis of fetal renal abnormalities. Best Pract Res Clin Obstet Gynaecol. 2014 Apr; 28(3):403-15.

6 Parikh CR, McCall D, Engelman C, Schrier RW. Congenital renal agenesis: case-control analysis of birth characteristics. Am J Kidney Dis. 2002 Apr;39(4):689-94.

7 Vanderheyden T, Kumar S, Fisk NM. Fetal renal impairment. Semin Neonatol. 2003 Aug; 8(4):279-89.

8 Vikraman SK, Chandra V, Balakrishnan B, Batra M, Sethumadhavan S, Patil SN, et al. Impact of antepartum diagnostic amnioinfusion on targeted ultrasound imaging of pregnancies presenting with severe oligo- and anhydramnios: an analysis of 61 cases. Eur J Obstet Gynecol Reprod Biol. 2017 May;212: 96-100.
9 Miller RS. Fetal lower urinary tract obstruction: an update. Open Urol Nephrol J. 2015; $8(1): 124-35$.

10 Bergmann C. Genetics of autosomal recessive polycystic kidney disease and its differential diagnoses. Front Pediatr. 2018 Feb;5:221.

11 Thakur P, Speer P, Rajkovic A. Novel mutation in the PKHD1 gene diagnosed prenatally in a fetus with autosomal recessive polycystic kidney disease. Case Rep Genet. 2014;2014: 517952.

12 Werner EF, Hauspurg A, Bienstock JL. Inutero treatment of bilateral renal agenesis: A threshold analysis of possible cost effectiveness. Obstet Gynecol Int J. 2015;2(3).

13 Perez-Brayfield MR, Kirsch AJ, Smith EA. Monoamniotic twin discordant for bilateral renal agenesis with normal pulmonary function. Urology. 2004 Sep;64(3):589.

14 Bienstock JL, Birsner ML, Coleman F, Hueppchen NA. Successful in utero intervention for bilateral renal agenesis. Obstet Gynecol. 2014 Aug;124(2 Pt 2 Suppl 1):413-5.

15 Cameron D, Lupton BA, Farquharson D, Hiruki T. Amnioinfusions in renal agenesis. Obstet Gynecol. 1994 May;83(5 Pt 2):872-6.

16 Whittaker N, Leonardi M. Five-Month Survival of Neonate After Serial Amnioinfusions for Fetal Bilateral Renal Agenesis [18D]. Obstet Gynecol. 2016;127:39S.

17 Barak H, Huh SH, Chen S, Jeanpierre C, Martinovic J, Parisot M, et al. FGF9 and FGF20 maintain the stemness of nephron progenitors in mice and man. Dev Cell. 2012 Jun; 22(6):1191-207.

18 Humbert C, Silbermann F, Morar B, Parisot M, Zarhrate M, Masson C, et al. Integrin alpha 8 recessive mutations are responsible for bilateral renal agenesis in humans. Am J Hum Genet. 2014 Feb;94(2):288-94.
19 Bullock SL, Fletcher JM, Beddington RS, Wilson VA. Renal agenesis in mice homozygous for a gene trap mutation in the gene encoding heparan sulfate 2-sulfotransferase. Genes Dev. 1998 Jun;12(12):1894-906.

20 Merry CL, Bullock SL, Swan DC, Backen AC, Lyon M, Beddington RS, et al. The molecular phenotype of heparan sulfate in the Hs2st-/mutant mouse. J Biol Chem. 2001 Sep; 276(38):35429-34.

21 Sánchez MP, Silos-Santiago I, Frisén J, He B, Lira SA, Barbacid M. Renal agenesis and the absence of enteric neurons in mice lacking GDNF. Nature. 1996 Jul;382(6586):70-

22 Harewood L, Liu M, Keeling J, Howatson A, Whiteford M, Branney P, et al. Bilateral renal agenesis/hypoplasia/dysplasia (BRAHD): postmortem analysis of 45 cases with breakpoint mapping of two de novo translocations. PLoS One. 2010 Aug;5(8):e12375.

23 Chiaramonte C, Bommarito D, Zambaiti E, Antona V, Li Voti G. Genetic Basis of Posterior Urethral Valves Inheritance. Urology. 2016 Sep;95:175-9.

24 Nakayama M, Nozu K, Goto Y, Kamei K, Ito $\mathrm{S}$, Sato $\mathrm{H}$, et al. HNF1B alterations associated with congenital anomalies of the kidney and urinary tract. Pediatr Nephrol. 2010 Jun; 25(6):1073-9.

25 Jain L, Eaton DC. Physiology of fetal lung fluid clearance and the effect of labor. Semin Perinatol. $2006 \mathrm{Feb} ; 30(1): 34-43$.

26 Polin RA, Fox WW, Abman SH. Fetal and Neonatal Physiology E-Book. Elsevier Health Sciences; 2011.

27 Hooper SB, Polglase GR, Roehr CC. Cardiopulmonary changes with aeration of the newborn lung. Paediatr Respir Rev. 2015 Jun; 16(3):147-50. 
28 Kitterman JA. The effects of mechanical forces on fetal lung growth. Clin Perinatol. 1996 Dec;23(4):727-40.

29 Alcorn D, Adamson TM, Lambert TF, Maloney JE, Ritchie BC, Robinson PM. Morphological effects of chronic tracheal ligation and drainage in the fetal lamb lung. J Anat. 1977 Jul;123(Pt 3):649-60.

30 Moessinger AC, Harding R, Adamson TM, Singh M, Kiu GT. Role of lung fluid volume in growth and maturation of the fetal sheep lung. J Clin Invest. 1990 Oct;86(4):1270-7.

31 Hooper SB, Harding R. Fetal lung liquid: a major determinant of the growth and functional development of the fetal lung. Clin Exp Pharmacol Physiol. 1995 Apr;22(4):235-47.

32 Adzick NS, Harrison MR, Glick PL, Villa RL, Finkbeiner W. Experimental pulmonary hypoplasia and oligohydramnios: relative contributions of lung fluid and fetal breathing movements. J Pediatr Surg. 1984 Dec;19(6): 658-65.

33 Turcios NL, Fink RJ. Pulmonary Manifestations of Pediatric Diseases E-Book. Elsevier Health Sciences; 2009.

34 Hislop A, Hey E, Reid L. The lungs in congenital bilateral renal agenesis and dysplasia. Arch Dis Child. 1979 Jan;54(1):32-8.

35 Kumar B, Alfirevic Z, editors. Fetal Medicine. Cambridge: Cambridge University Press; 2016. p. 151.

36 Teh JC, Frieling ML, Sienna JL, Geary DF. Attitudes of caregivers to management of endstage renal disease in infants. Perit Dial Int. 2011 Jul-Aug;31(4):459-65.

37 Rees L. Renal replacement therapies in neonates: issues and ethics. Semin Fetal Neonatal Med. 2017 Apr;22(2):104-8.

38 Carey WA, Talley LI, Sehring SA, Jaskula JM, Mathias RS. Outcomes of dialysis initiated during the neonatal period for treatment of end-stage renal disease: a North American Pediatric Renal Trials and Collaborative
Studies special analysis. Pediatrics. 2007 Feb; 119(2):e468-73.

39 Lantos JD, Warady BA. The evolving ethics of infant dialysis. Pediatr Nephrol. 2013 Oct; 28(10):1943-7.

40 Wightman AG, Freeman MA. Update on eth ical issues in pediatric dialysis: has pediatric dialysis become morally obligatory? Clin J Am Soc Nephrol. 2016 Aug;11(8):1456-62.

41 Wedekin M, Ehrich JH, Offner G, Pape L. Renal replacement therapy in infants with chronic renal failure in the first year of life. Clin J Am Soc Nephrol. 2010 Jan;5(1):18-23.

42 Gupta C, Moudgil A. Renal transplantation in children: current status and challenges. Apollo Medicine. 2017;14(2):88-99.

43 USRDS. U. Annual data report: atlas of chronic kidney disease and end-stage renal disease in the United States. National Institutes of Health, National Institute of Diabetes and Digestive and Kidney Diseases; 2013.

44 Locatelli A, Vergani P, Di Pirro G, Doria V, Biffi A, Ghidini A. Role of amnioinfusion in the management of premature rupture of the membranes at $[\{\mathrm{LT}\}] 26$ weeks' gestation. Am J Obstet Gynecol. 2000 Oct;183(4):878-82.

45 Haeri S, Simon DH, Pillutla K. Serial amnioinfusions for fetal pulmonary palliation in $\mathrm{fe}$ tuses with renal failure. J Matern Fetal Neonatal Med. 2017 Jan;30(2):174-6.

46 Sugarman J, Anderson J, Baschat AA, Herrera Beutler J, Bienstock JL, Bunchman TE, et al. Ethical considerations concerning amnioinfusions for treating Fetal Bilateral Renal Agenesis. Obstet Gynecol. 2018 Jan;131(1):130-4.

47 Symons JM, Brophy PD, Gregory MJ, McAfee N, Somers MJ, Bunchman TE, et al. Continuous renal replacement therapy in children up to $10 \mathrm{~kg}$. Am J Kidney Dis. 2003 May;41(5):984-9.

48 Al-Hermi BE, Al-Saran K, Secker D, Geary DF. Hemodialysis for end-stage renal disease in children weighing less than $10 \mathrm{~kg}$. Pediatr Nephrol. 1999 Jun;13(5):401-3.
49 Warady BA. Peritoneal dialysis and the pediatric patient. Perit Dial Int. 2012 Jul-Aug; 32(4):393-4.

50 Rees L. Management of the infant with endstage renal failure. Nephrol Dial Transplant. 2002 Sep;17(9):1564-7.

51 Chavers BM, Rheault MN, Matas AJ, Jackson SC, Cook ME, Nevins TE, et al. Improved outcomes of kidney transplantation in infants (age 2 years): A single-center experience. Transplantation. 2018 Feb;102(2):284-90.

52 Humar A, Arrazola L, Mauer M, Matas AJ, Najarian JS. Kidney transplantation in young children: should there be a minimum age? Pediatr Nephrol. 2001 Dec;16(12):941-5.

53 Jalanko H, Mattila I, Holmberg C. Renal transplantation in infants. Pediatr Nephrol. 2016 May;31(5):725-35.

54 Bartosh S, Dipchand A, Chavers B. Pediatric kidney transplantation: a guide for families. American Society of Transplantation; 2015.

55 Cousino MK, Hazen RA. Parenting stress among caregivers of children with chronic illness: a systematic review. J Pediatr Psychol. 2013 Sep;38(8):809-28.

56 Geense WW, van Gaal BG, Knoll JL, Cornelissen EA, van Achterberg T. The support needs of parents having a child with a chronic kidney disease: a focus group study. Child Care Health Dev. 2017 Nov;43(6):831-8.

57 Galla JH; The Renal Physicians Association and the American Society of Nephrology. Clinical practice guideline on shared decision-making in the appropriate initiation of and withdrawal from dialysis. J Am Soc Nephrol. 2000 Jul;11(7):1340-2.

58 https://www.medicare.gov/Pubs/pdf/10050Medicare-and-You.pdf.

59 Moxey-Mims M, Raju TN. Anhydramnios in the setting of renal malformations: The National Institutes of Health workshop summary. Obstet Gynecol. 2018 Jun;131(6): 1069-79. 